BMJ Open Sport \& Exercise Medicine

\title{
Exercise genetics: seeking clarity from noise
}

Craig Pickering, ${ }^{1,2}$ John Kiely ${ }^{1}$

To cite: Pickering C, Kiely J. Exercise genetics: seeking clarity from noise. BMJ Open Sport \& Exercise Medicine 2017;3:e000309. doi:10.1136/ bmjsem-2017-000309

Accepted 3 November 2017

\section{CrossMark}

${ }^{1}$ School of Sport and Wellbeing, Institute of Coaching and Performance, University of Central Lancashire, Preston, UK ${ }^{2}$ Exercise and Nutritional Genomics Research Centre, DNAFit Ltd, London, UK

Correspondence to Mr Craig Pickering; craig@ dnafit.com
The potential of recent advances in genetics research to supplement elite sport decision-making has potentially extensive implications, but remains highly controversial. One potential application is the use of genetic information to enhance exercise prescription, thereby positively influencing athletic performance and public health domains. Recent research suggests that this is both feasible and potentially beneficial. ${ }^{12}$ However, such an effective use of genetic information requires a clear understanding of the mechanism by which each reported single nucleotide polymorphism (SNP) mediates physical performance. In the absence of such a clear, mechanistic explanation, we are left with vague associations without causative roots. While uncovering gene associations is necessary, it is not sufficient to presume causation. Given the complex entangled routes through which genes and environment interact to express phenotype, superficial association-based logical inferences are likely to be misleading.

\section{ASSOCIATION OR CAUSATION?}

As an example, within the HEalth, RIsk factors, exercise Training And GEnetics (HERITAGE) Family Study, variation in CREB1 (rs2253206) predicted heart rate (HR) response to exercise. ${ }^{3}$ Specifically, the A allele associated with a smaller reduction in HR during a submaximal exercise test following training, with the proposed mechanism relating to longterm cardiac memory. However, research in a separate cohort associated the A allele with a greater exercise-induced temperature increase- contributing to a less pleasant subjective experience of exercise, potentially reducing motivation to train or carry out an aerobic test. ${ }^{4}$ Accordingly, it is unclear whether HR responsiveness was modified via biologically mediated adaptations or an increased perception of effort.

Similarly, a SNP within COL5A1-rs12722has been linked to exercise-associated muscle cramps (EAMC), with the CC genotype associated with protection from EAMC during an ultra-marathon. ${ }^{5}$ However, CG genotypes also recorded significantly slower ultra-marathon times compared with TT genotypes. ${ }^{5}$ Does this genetic variation directly protect against EAMC or does it result in slower race times, which, given that EAMC is associated with increased neuromuscular fatigue, is what acts in a protective manner? Again, the biological impact of this SNP on EAMC is not clear, requiring more evidence before advice can be given.

\section{ARE THESE RELATIONSHIPS CONSISTENT?}

In addition to resolving the biological mechanisms underpinning the impact of genetic variation on exercise, we must also consider whether these genetic associations are consistent over time and across different cohorts. Much is made of non-responders to exercise, and yet is unclear whether this non-response is consistent, or whether it is a one-time response to an intervention. In addition, it is unclear whether SNPs associated with exercise response in sedentary individuals have similar effects in trained subjects. An SNP in ACSL1, rs6552828, had the strongest association with training-induced $\mathrm{VO}_{2 \max }$ improvements in HERITAGE, ${ }^{6}$ a sedentary cohort. However, in an elite athlete cohort, there was no association between this SNP and elite endurance status (a proxy of high $\mathrm{VO}_{2 \max }$ ) in Caucasians. ${ }^{7}$ No further ACSL1 replications exist. Does variation in ACSL1 impact exercise adaptation in all humans or only the subset of humans who took part in HERITAGE? If HERITAGE were to be repeated with the same subjects, would the ACSL1 and aerobic fitness association remain constant? Does this variation affect trained and untrained subjects to the same extent? Answers to these questions are needed before these SNPs should be used to modify the training process.

\section{EFFECTIVE UTILISATION}

Despite these issues, there are a number of SNPs in which the biological mechanisms are well understood. A common SNP in ACTN3, the gene that encodes for $\alpha$-actinin- 3 , a protein found exclusively in fast-twitch muscle fibres, results in a premature stop 
codon. Individuals homozygous for this polymorphism are unable to produce the protein, and as a result tend to have fewer fast-twitch fibres. ${ }^{8}$ This in turn affects the response to strength training. ${ }^{9}$ The utilisation of this information holds promise; a recent paper used this SNP in conjunction with 14 others to enhance resistance training response, ${ }^{2}$ and evidence-based guidelines have been proposed. ${ }^{10}$ This underscores both the effectiveness and the utility of genetic information in informing training methodologies when the biological mechanism is well understood.

\section{SUMMARY}

Research into the genetics of exercise adaptation is both exciting and promising. As each SNP exerts its influence potentially through a multitude of pathways, some identified gene-trait associations may be spurious. Conceptual clarity therefore requires that the causative mechanisms directly linking genotype to phenotype are more clearly deciphered; simply revealing associations are insufficient when the aim is to better inform practice.

Perspectives on the promise of exercise genetics vary widely, with polarised extremes of staunch advocates and deniers. For the majority, the complex relationship between genotype and phenotype promotes a healthy scepticism; nevertheless, a total rejection of the potential utility of gene panels to categorise adaptive subtypes, given promising preliminary findings, ${ }^{1}{ }^{2}{ }^{10}$ is premature. Beyond a formulaic statement of the obvious-that correlation is not causation-it seems wise to proceed cautiously, sceptically, but with an open mind as more evidence unfolds.

Contributors $\mathrm{CP}$ conceived the idea for this manuscript and wrote the first draft. JK provided feedback on the initial idea, first draft and rewrote large parts of final draft. Both authors gave final approval for the version to be published.

Competing interests CP is an employee of DNAFit Ltd. He received no financial incentive for the production of this manuscript which was produced as part of his Professional Doctorate studies.

\section{Provenance and peer review Not commissioned; internally peer reviewed.}

Open Access This is an Open Access article distributed in accordance with the Creative Commons Attribution Non Commercial (CC BY-NC 4.0) license, which permits others to distribute, remix, adapt, build upon this work non-commercially, and license their derivative works on different terms, provided the original work is properly cited and the use is non-commercial. See: http://creativecommons.org/ licenses/by-nc/4.0/

(C) Article author(s) (or their employer(s) unless otherwise stated in the text of the article) 2017. All rights reserved. No commercial use is permitted unless otherwise expressly granted.

\section{REFERENCES}

1 Timmons JA, Knudsen S, Rankinen T, et al. Using molecular classification to predict gains in maximal aerobic capacity following endurance exercise training in humans. J Appl Physiol 2010;108:1487-96.

2 Jones N, Kiely J, Suraci B, et al. A genetic-based algorithm for personalized resistance training. Biol Sport 2016;33:117-26.

3 Rankinen T, Argyropoulos G, Rice T, et al. CREB1 is a strong genetic predictor of the variation in exercise heart rate response to regular exercise: the HERITAGE Family Study. Circ Cardiovasc Genet 2010;3:294-9.

4 Karoly HC, Stevens CJ, Magnan RE, et al. Genetic influences on physiological and subjective responses to an aerobic exercise session among sedentary adults. J Cancer Epidemiol 2012;2012:1-12.

5. O'Connell K, Posthumus M, Schwellnus MP, et al. Collagen genes and exercise-associated muscle cramping. Clin J Sport Med 2013;23:64-9.

6. Bouchard C, Sarzynski MA, Rice TK, et al. Genomic predictors of the maximal $\mathrm{O} \square$ uptake response to standardized exercise training programs. J Appl Physiol 2011;110:1160-70.

7 Yvert T, He ZH, Santiago C, et al. Acyl coenzyme A synthetase long-chain 1 (ACSL1) gene polymorphism (rs6552828) and elite endurance athletic status: a replication study. PLOS One 2012;7:e41268.

8 Vincent B, De Bock K, Ramaekers M, et al. ACTN3 (R577X) genotype is associated with fiber type distribution. Physiol Genomics 2007;32:58-63.

9 Delmonico MJ, Kostek MC, Doldo NA, et al. Alpha-actinin-3 (ACTN3) R577X polymorphism influences knee extensor peak power response to strength training in older men and women. $J$ Gerontol A Biol Sci Med Sci 2007;62:206-12.

10 Kikuchi N, Nakazato K. Effective utilization of genetic information for athletes and coaches: focus on ACTN3 R577X polymorphism. $J$ Exerc Nutrition Biochem 2015;19:157-64. 